\title{
Flow over Heated Terrain. Part II: Generation of Convective Precipitation
}

\author{
DONNA F. TUCKER \\ Department of Geography, University of Kansas, Lawrence, Kansas \\ N. ANDREW CROOK \\ National Center for Atmospheric Research, Boulder, Colorado
}

(Manuscript received 30 March 2004, in final form 20 January 2005)

\begin{abstract}
Previous studies have shown that thunderstorms in the Rocky Mountain region have preferred areas in which to form. There has been some indication that these areas depend on the midtropospheric wind direction. A nonhydrostatic model with a terrain-following horizontal grid is employed to investigate the initiation of precipitating convection over heated topography. Horizontally homogeneous meteorological conditions with no directional shear in the vertical wind profile are used.

The numerical simulations indicate that precipitating convection was more likely to be generated downwind of ridges than upwind of them. Initiation of these storms was more likely downwind of ridges with their long axis parallel to the wind direction than downwind of ridges with their long axis perpendicular to the wind direction. In Part I of this study it was shown that heating-induced convergence is larger downwind of a ridge with its longer axis parallel to the wind direction. For the orographic configuration of the Rocky Mountains, total precipitation is maximized for southerly and northwesterly winds. Slower wind speeds are more likely and faster wind speeds are less likely to produce convective storms. Soundings with larger instability are more likely to produce convection. The soundings with a greater temperature lapse rate produce more initiation locations, and soundings with greater moisture produce greater amounts of precipitation.

Even though a number of assumptions were made for this study, the authors believe the results explain a significant amount of the observed variability in the initiation locations of precipitating convection in the Rocky Mountains during the summer. Because of the theoretical basis for this work, detailed in Part I of this study, the authors believe it should explain convective initiation in other mountainous areas that are subject to strong solar heating.
\end{abstract}

\section{Introduction}

A number of investigators have reported that summer thunderstorms in the Rocky Mountain region have preferred locations in which to form. Early studies with radar (Henz 1973; Karr and Wooten 1976) revealed favorable areas were especially likely to be on mountaintops or ridgetops. Investigations that traced convective activity through lightning strikes (Lopez and Holle 1986; Reap 1986) produced results that were similar to those done by radar-based studies. Klitch et al. (1985) relied on satellite composites to reveal the preferred

Corresponding author address: Donna Tucker, Department of Geography, 1475 Jayhawk Blvd., 213 Lindley Hall, University of Kansas, Lawrence, KS 66049.

E-mail: dtucker@ku.edu areas for convective initiation. Their study presented evidence that the most favorable regions for thunderstorm initiation were so, not because of elevation alone, but also because of steep slope angles.

A detailed study of this problem was performed by Banta and Schaaf (1987) who traced individual thunderstorms back to their points of origin in the central Rocky Mountains over a period of three summers. They not only found that there were preferred regions of thunderstorm formation but that these areas varied with the prevailing wind direction. Convective development was more favored in the southern part of the domain during northwest flow and in the northern part of the domain under southerly flow with mixed zonal wind components. Their investigation found that the lee side of mountain ranges was often favored for thunderstorm genesis. 
Although a number of these studies speculated on the cause of these preferred locations of convective initiation, none of them had a methodology that would allow them to determine what physical processes were most important. One difficulty with making this determination is that a large number of processes encourage the development of convective activity in mountainous areas. Summaries of these processes are given by Banta (1990) and Johnson and Mapes (2001). Mechanical lifting may cause air parcels to reach their level of free convection or may cause the creation of instability in a potentially unstable layer. Mountains can generate convergence by acting as an obstacle. Examples include channeling by narrowing mountain valleys, air going around a mountain and converging on the lee side, blocking, and downstream eddies such as the Denver Cyclone (Szoke et al. 1984). Gravity waves generated by mountains can encourage the development of convection especially if they interact with other mountaingenerated flows (Tripoli and Cotton 1989a,b). In addition, mountains can act as an elevated heat or cold source. This process causes upslope and upvalley winds during the day. In the absence of a large-scale flow, upslope flows on all sides of a mountain create convergence at mountaintop. If a large-scale flow exists, then this convergence moves to the lee side of the mountain. At night, downslope flows into a valley surrounded by mountains can generate thunderstorms (Tucker 1993). Over larger time and space scales this elevated heating and cooling can cause plateau circulation systems (Tang and Reiter 1984; Reiter and Tang 1984).

In the first part of this study (Crook and Tucker 2005, hereafter referred to as Part I), the lifting generated by flow past a heated mountain was examined with both linear and nonlinear models. It was shown that the lifting in the lee increases as the heating rate and obstacle width increase, and as the upstream wind speed and stability decrease. It was also shown that for elliptically shaped obstacles such as a ridge, the lifting is maximized when the flow is along the ridge.

This study explores precipitation patterns produced by flow over both idealized terrain and an actual mountain system, the Rocky Mountains of the United States. It employs a numerical model to present evidence that the primary cause of the observed favored locations for thunderstorm initiation within the central Rocky Mountains is the convergence generated in the lee of heated terrain features. This effect is maximized when the winds are weaker and have a relatively longer fetch over the higher terrain. The implications of these findings for precipitation patterns in the Rocky Mountain region are explored.

\section{Experimental design}

This investigation employed the anelastic, nonhydrostatic numerical model described by Clark and Hall (1991). It uses a terrain-following grid in the horizontal and employs a stretched grid in the vertical (Clark and Hall 1996). The model includes an ice microphysics parameterization scheme (Koenig and Murray 1976) that includes homogeneous and heterogeneous nucleation of ice, growth of ice crystals by diffusion and sublimation, accretional growth of ice, and melting of ice. Turbulent fluxes are calculated with a first-order closure scheme of Lilly (1962) and Smagorinsky (1963). Radiative cooling in the atmosphere is determined from the broadband emittance method given by Stephens (1984). Solar radiation received at the earth's surface is dependent on the slope and aspect of the earth's surface as well as the sun angle. The surface fluxes of heat and moisture are calculated as a percentage of the incoming solar radiation absorbed by the earth's surface. In the simulations presented herein the Bowen ratio is set to 1 across the whole domain.

All experiments are initialized from a single sounding; see Fig. 1. For simplicity, the wind profile has no directional shear, only speed shear. Experiments are then performed with the wind direction varying from southerly to northwesterly in order to examine the sensitivity of the precipitation field on the wind direction. The speed shear was determined from $10 \mathrm{yr}$ (1976-85) of Denver radiosonde data. Soundings were included if they fell into one of the three categories chosen by Banta and Schaaf (1987). Shear in each category was averaged and shear used here is the average of those three categories. It is recognized that some of the categories were more common than others but we wanted shear to include effects of all categories. The sounding is somewhat more unstable (CAPE $=57 \mathrm{~J} \mathrm{~kg}^{-1}$ ) than the average summer sounding in eastern Colorado at this time, 0600 LT (1200 UTC), but well within the normal range. This slightly unstable sounding was chosen to maximize the amount of precipitation and reveal the greatest number of convective initiation points. It should be noted that the CAPE of $57 \mathrm{~J} \mathrm{~kg}^{-1}$ is for a surface parcel at $828 \mathrm{mb}$ - pressure at the elevation of the mountains would be less. In addition, surface heating and moistening increase the value of CAPE considerably during the day. Generally, in the Rocky Mountain region in the summer, more northerly flow is associated with less moisture, greater stability, and stronger winds than the more southerly flows. We have not included these differences in this work and have sought to examine all flows on an equal basis. It should be noted that the low relative humidities in this sound- 


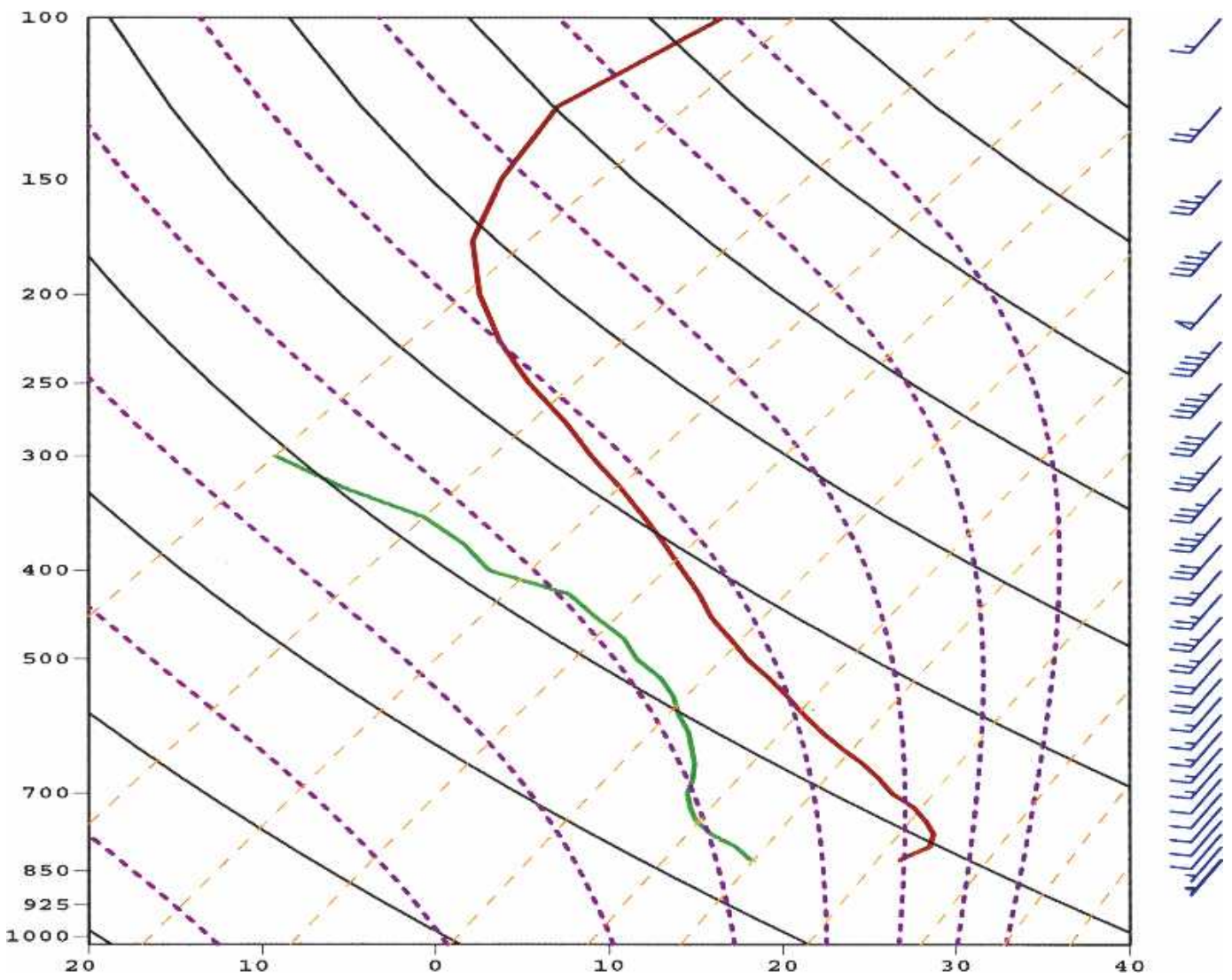

FIG. 1. Skew $T-\log p$ diagram showing the temperature, dewpoint, and wind profile used in model simulations.

ing do not encourage the development of stratiform clouds. These humidity conditions are typical in this region during the summer and result in strong solar heating of the surface during the day. A diurnal cycle was included in the simulations, and all simulations started at 1200 UTC.

In the Clark-Hall model, at least when run with a single mean sounding, the Coriolis force is only applied to perturbations of the wind from the mean sounding. In other words, the pressure gradient that balances the mean-state wind field is implicit, not explicitly calculated. If there is vertical shear in the mean-state wind field, then there should be a temperature gradient perpendicular to that shear (the thermal wind balance). This temperature gradient is not included in the present simulations. Although this is a simplification, it does allow us to avoid the complication of having a meanstate temperature profile that varies horizontally. This would lead to different convective responses in different parts of the domain given the same forcing. Thus, including this temperature gradient would make the interpretation of the results unclear. Furthermore, the temperature gradient at low levels in thermal wind bal- ance with the wind profile shown in Fig. 1 is fairly small; in the $700-500-\mathrm{hPa}$ layer it is equivalent to approximately $2^{\circ} \mathrm{C}$ difference across the inner domain. At lower levels, where the model would be more sensitive, this temperature difference would be less. The actual difference is difficult to estimate in the boundary layer due to the effect of friction. The relatively small amount of shear at low levels also allows us to use the results from Part I that assumed a uniform upstream wind profile.

\section{Idealized terrain simulations}

We first examine the moist convective response to flow over idealized terrain. In Part I, it was shown that the maximum in lifting occurs when the flow is along the major axis of a heated obstacle. In the present simulations, the obstacle is elliptically shaped with a major axis length of $40 \mathrm{~km}$ and a minor axis length of $10 \mathrm{~km}$. The obstacle is $1 \mathrm{~km}$ high and rises above the plains at $1.5 \mathrm{~km}$ AGL (to make it easier to compare with simulations of the Rocky Mountains described later). The grid spacing in the horizontal is $2 \mathrm{~km}$; in the vertical it 
is stretched from $50 \mathrm{~m}$ at the surface to $500 \mathrm{~m}$ at the model top of $18 \mathrm{~km}$.

Figure 2 shows the 5-h accumulated precipitation when the flow is (a) along the major axis and (b) across the major axis of the obstacle. For flow along the ridge, the precipitation develops in a narrow band on the downwind slope of the ridge in the same location as the vertical velocity maximum shown in Fig. 12a of Part I. When the flow is across the ridge, the accumulation is much weaker and develops some distance downwind of the obstacle. Note that the "V shape" in the precipitation pattern corresponds to the shape of the gravity wave updraft in the lee of the obstacle (a vertical cross section through that updraft in shown in Fig. 12b of Part I). As shown in Part I, when the flow is across a heated ridge, the orographically forced gravity wave response dominates.

The horizontally integrated accumulation of precipitation is listed above each panel. The fact that the lowlevel lifting is much stronger when the flow is along the ridge is shown in the result that the total accumulation is 7.5 times greater when the flow is along the ridge compared to across the ridge. To further examine this

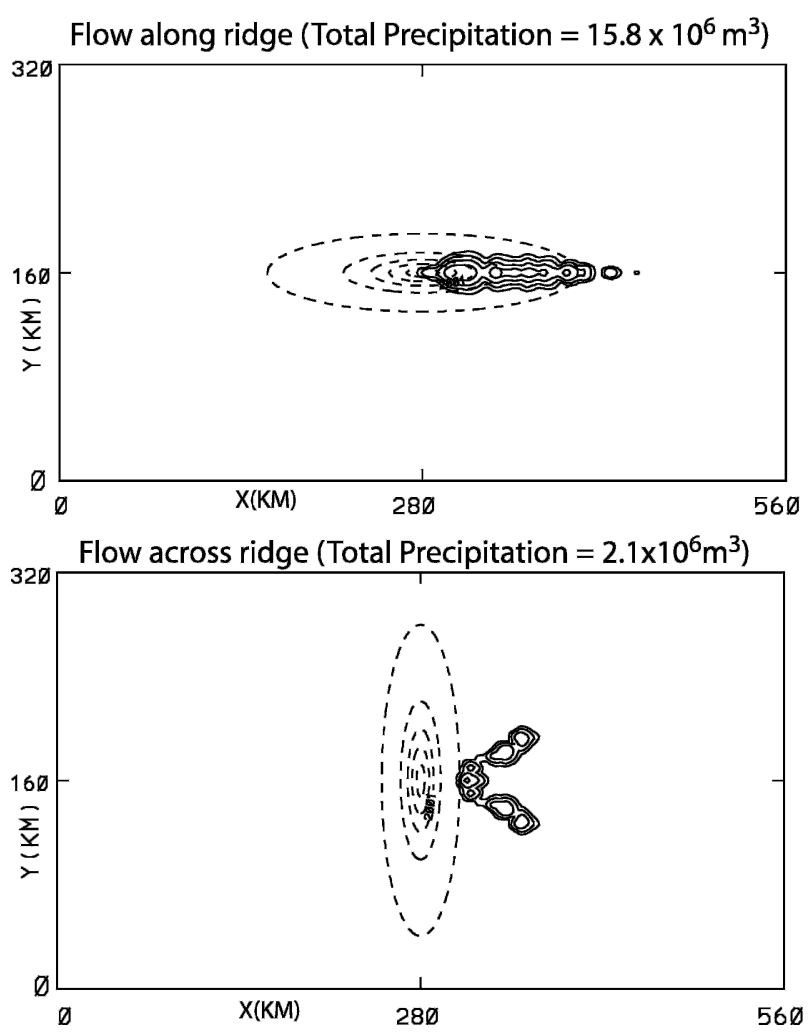

FIG. 2. Accumulated precipitation for moist convective flow (a) along and (b) across an elliptically shaped heated obstacle. Contours are in multiples of 10 , starting at $10^{-3} \mathrm{~cm}$. sensitivity, experiments were run with varying angles of the mean flow to the major axis of the obstacle. Figure 3 is a plot of the total accumulation against the angle between mean flow and major axis and shows a monotonic decrease of the accumulated precipitation as the angle increases from $0^{\circ}$ to $90^{\circ}$.

To further explore the reason for the different moist convective response when the flow is along versus across a heated ridge, soundings were calculated for two cases at $t=120 \mathrm{~min}$, just before the development of moist convection. The temperature and moisture fields were averaged over a $20-\mathrm{km}$ box, the center of which was located $20 \mathrm{~km}$ downwind of the obstacle's peak. The soundings are shown in Fig. 4 (solid lines for flow along the ridge; dashed lines for flow across the ridge). As can be seen, the temperature profiles for the two cases are quite similar, with the across flow case being slightly warmer (by an average of $0.3^{\circ} \mathrm{C}$ in the lower 2 $\mathrm{km}$ of the atmosphere). Since the soundings are calculated at the same time the amount of heat put into the lower atmosphere is the same in both cases. However, as noted in Part I, the major difference between the two cases is that when the flow is along the ridge the crossstream baroclinicity that develops is larger since the elevated heating drops off faster away from the obstacle's centerline. This in turn drives a cross-stream circulation that increases the vertical velocity in the lee when the flow is along the ridge. This lifting produces
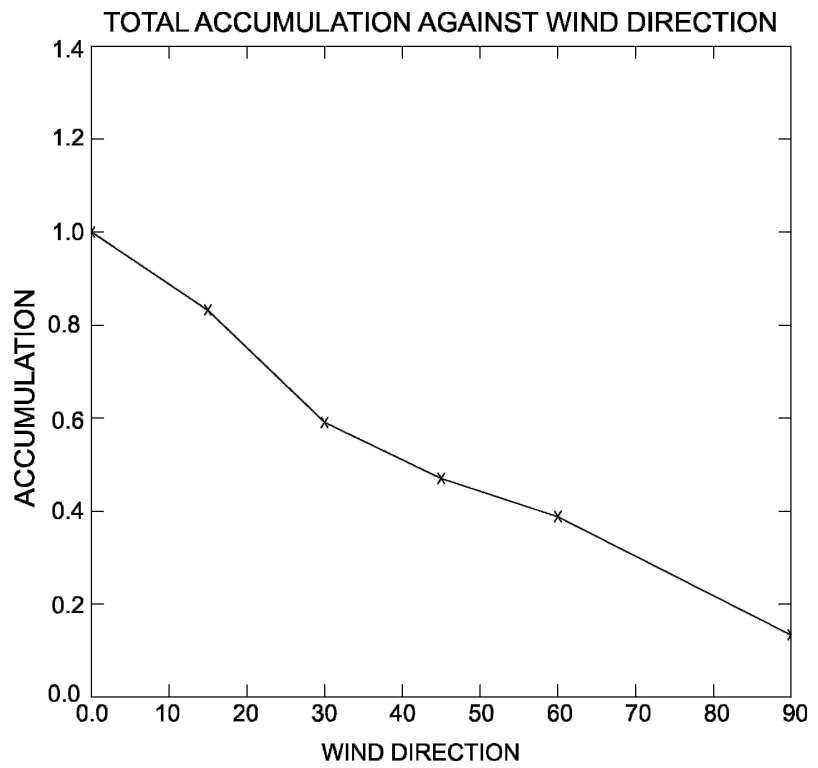

FIG. 3. Total accumulation of precipitation as a function of wind direction relative to the major axis of a heated obstacle. Accumulation is over $5 \mathrm{~h}$ and is normalized by the value in the along-ridge experiment $\left(0^{\circ}\right)$. 


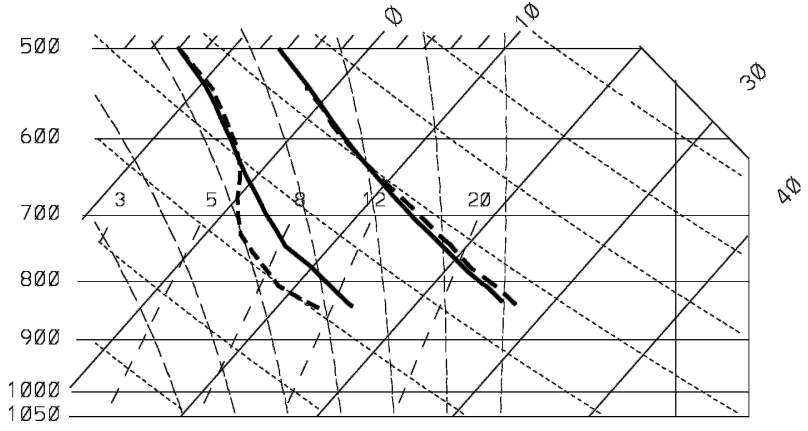

FIG. 4. Skew $T$ diagram showing temperature and humidity structure downwind of ridge when flow is along (solid) and across (dashed) the ridge.

some adiabatic cooling, which explains the fact that temperature profile in the along-ridge case is slightly cooler than the across-flow case. However, this effect is quite small, since the stratification at this time just before moist convection develops is nearly dry adiabatic. The major effect of the increased lifting can be seen in the moisture profiles; the moisture is much deeper in the case of flow along a ridge, and consequently the moist convective response is greater.

\section{Complex terrain simulations}

We now examine whether a similar sensitivity to wind direction occurs for flow over complex terrain. A grid structure has been chosen with two grids. The inner domain has a spacing of $2.6 \mathrm{~km}$ and covers central and western Colorado and northern New Mexico. The outer domain has a spacing of $7.8 \mathrm{~km}$ and covers a wider portion of the western United States. The inner domain is located off center to the east in the outer grid as no simulations with easterly winds are done. Output will be shown from the inner domain only. The vertical grid is the same as in the idealized simulations. The topography of the inner domain with key features annotated is shown in Fig. 5.

We first examined the climatological frequency of various wind directions in the region of the Rocky Mountains. The 500-mb wind directions for Denver have been collected for the period 1972-2001 for the months of June, July, and August. The frequency with which each wind direction occurs at Denver during the summer months is given in Fig. 6. It can be seen that the mode of this distribution is at $250^{\circ}$, easterly winds rarely occur, and northwesterly winds are slightly more common than southwesterly winds. Wind directions presented below were chosen to illustrate the variability in the precipitation produced between the different wind directions observed in the region during the summer.

Twelve hours of simulation have been performed for eight wind directions. The 12-h simulation of the precipitation accumulation for five of these directions $\left[180^{\circ}, 210^{\circ}, 225^{\circ}, 270^{\circ}\right.$, and $\left.315^{\circ}\right]$ is presented in Fig. 7. The total precipitation over the grid, the number of grid points with at least $0.5 \times 10^{-3} \mathrm{~m}$ of precipitation, the precipitation per grid point with precipitation, and the number of grid points with at least $10 \mathrm{~mm}$ of precipitation are presented for all cases studied in Table 1. In calculating the number of grid points with at least 10 $\mathrm{mm}$ of precipitation we have excluded the 20 grid points on the southern and western boundaries to avoid some minor boundary effects. Note that qualitatively, the simulation with winds from $225^{\circ}$ and the simulation with winds from $240^{\circ}$ were quite similar. Likewise, simulations from $300^{\circ}, 315^{\circ}$, and $330^{\circ}$ had a large amount of qualitative similarity.

In each of the cases shown in Fig. 7, a number of precipitation streaks have developed that are generally aligned with the large-scale wind. Some of these streaks are quite short while others extend for hundreds of kilometers downstream. In most cases, these precipitation streaks can be associated with an upstream terrain feature. But not all areas of high terrain act as initiation sites. Furthermore, the direction of the wind is important; some areas act as initiation sites in one direction but not in others. Therefore it is not simply the absolute height of the terrain that determines whether a precipitation streak will be triggered. One general area in the northern San Juan Mountains appears to be able to trigger convection from all directions. The San Juan Mountains are more isotropic and also cover more area than most other mountain ranges in the domain. The results suggest that some minimum fetch over terrain of some minimum height is needed for convective initiation to take place. Most terrain configurations can provide this minimum fetch in only particular directions. This behavior is consistent with the results in Part I where we showed that the lifting is maximized when the wind direction is along the long axis of the mountain. We now examine these initiation locations in more detail.

\section{a. Southerly flow}

The precipitation produced by the flow from $180^{\circ}$ has a comparatively large number of initiation locations, a fairly large amount of precipitation, and one of the higher amounts of precipitation per grid box. The number of grid boxes with greater than $10 \mathrm{~mm}$ of precipitation is substantially larger than for the other wind directions. This result is not surprising since the Rocky 


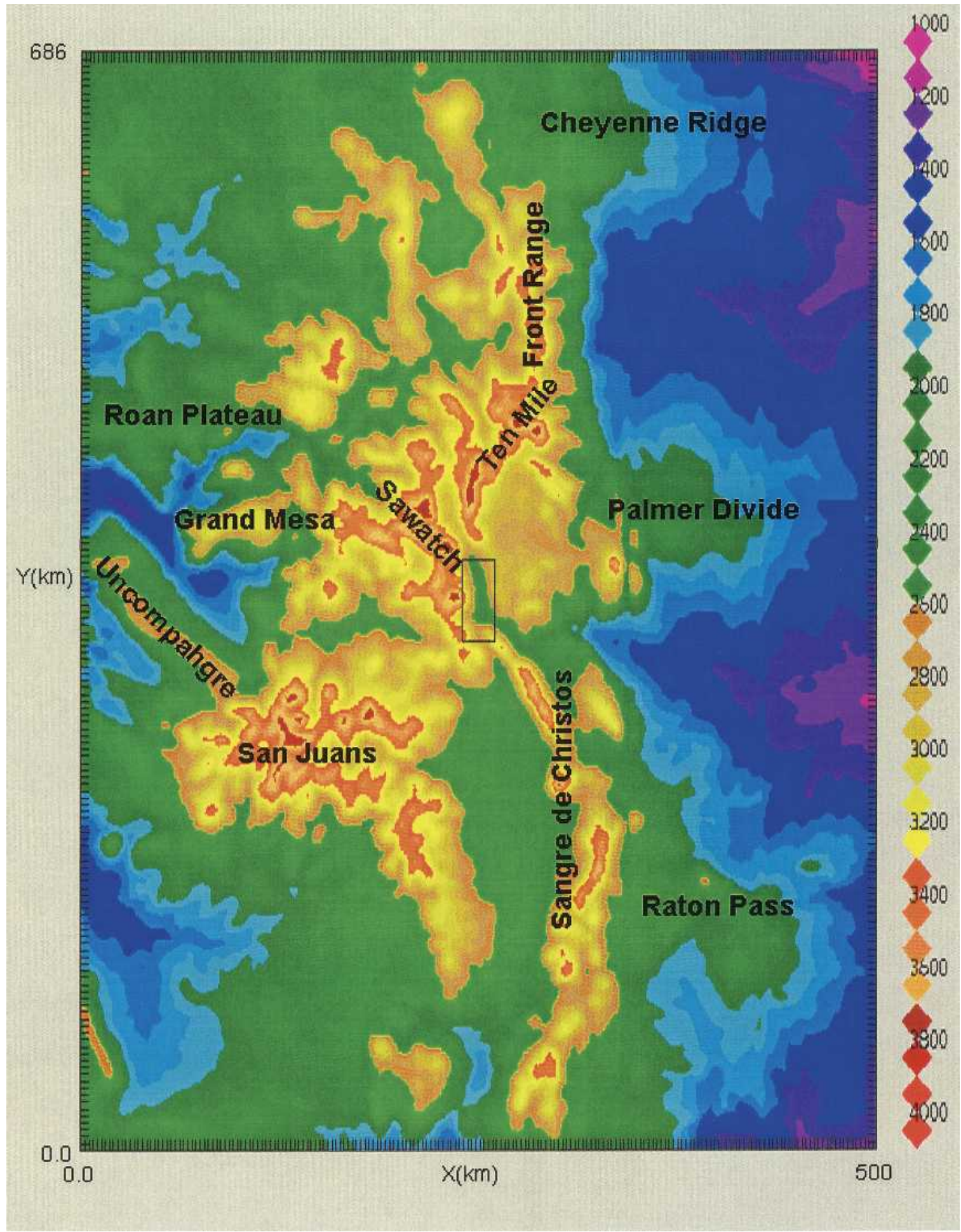

FIG. 5. Orography of the inner grid with elevations in meters and key features annotated.

Mountains are primarily a north-south barrier. There is little spread of the precipitation to the plains adjacent to the mountains. With this wind direction, convection can be generated by one ridge and then have a good chance to be reinvigorated by passing over another ridge farther downstream. With a high number of grid points with over $10 \mathrm{~mm}$ of precipitation this wind direction would have a greater than average potential to 


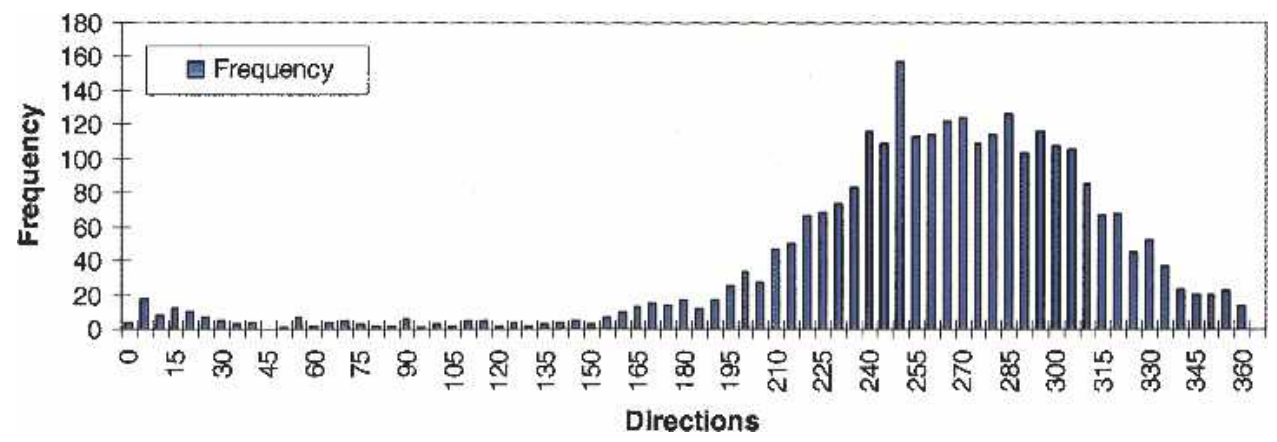

FIG. 6. Frequency of occurrence of wind direction at $500 \mathrm{mb}$ at Denver during Jun-Aug of 1973-2002.

produce heavy rainfall leading to flash floods if sufficient moisture is present. A negatively tilted $500-\mathrm{mb}$ trough centered over the central Great Plains is a favorable feature for flash-flood-producing storms in the eastern Rocky Mountains and adjacent plains (Maddox et al. 1980). Such a trough would be associated with a wind direction of close to $180^{\circ}$ in the eastern Rocky Mountain region. Southerly winds generally bring more atmospheric moisture and are associated with higher dewpoints than northerly winds. Convective initiation locations are favored in the most southern part of the domain, especially in the Sangre de Christo Range, as well as the north-central part of the domain. The northsouth-oriented Park Range generates precipitation with winds in this direction. The northwest part of the domain has almost no initiation locations.

\section{b. Southwesterly flow}

The flow from $210^{\circ}$ has about the same number of initiation locations as $180^{\circ}$ but has a lower amount of total precipitation integrated over the domain. This wind direction is particularly adept at generating precipitating systems off the Ten Mile ridge and the Front Range as well as the Sangre de Christo Range. The western part of the domain generates fewer and weaker convective storms than the eastern part. A large swath of precipitation develops which starts in the lee of the San Juan Mountains and then gets reinvigorated by the Ten Mile Range. It then extends out over the plains and generates an organized convective system that moves over the Denver metropolitan area. This simulation has a relatively large amount of precipitation per grid box but few grid boxes with over $10 \mathrm{~mm}$ of precipitation. The greater potential for convective storms to be invigorated and organized allows this flow pattern to generate moderate precipitation over a large area.

The simulation with the flow from $225^{\circ}$ has a fairly low number of convective initiation locations. Those few locations produce only moderate amounts of pre- cipitation, giving this simulation one of the lower amounts of precipitation per grid box and few grid boxes with over $10 \mathrm{~mm}$ of precipitation. Storms initiating at some locations are relatively long lasting. Thus, this wind direction has the least potential to produce precipitation, although it is favorable for a few locations, such as just north of the Palmer Divide. Winds from this direction and from $240^{\circ}$, which has a similar accumulation pattern, occur moderately frequently in this region during the summer yet they are the least favorable for producing precipitation over a wide area.

\section{c. Westerly flow}

Likewise the flow from $270^{\circ}$ has relatively few convective initiation locations in the mountains. However, it does have many initiation locations on the plains directly adjacent to the mountains. Many of these storms generated on the plains are weak and short-lived but there are a large number of them. The Sawatch Range and Palmer Divide, however, are able to generate a couple of storms that propagate well out into the plains. But in the mountains this flow generates a fairly substantial amount of precipitation per initiation location. Although these places are few, several of them have a moderately large amount of precipitation associated with them. Some of the initiation locations are in the northwestern part of the domain where the southerly flows have difficulty producing precipitation. Since this flow pattern has a tendency to be associated with larger amounts of precipitation per convective initiation location in few specific locations, several places could be subject to heavy precipitation and flash flooding with this flow if sufficient moisture is present when this flow predominates.

\section{d. Northwesterly flow}

The highest amount of total precipitation (of directions shown in Fig. 7) was produced by the flow 
(a)

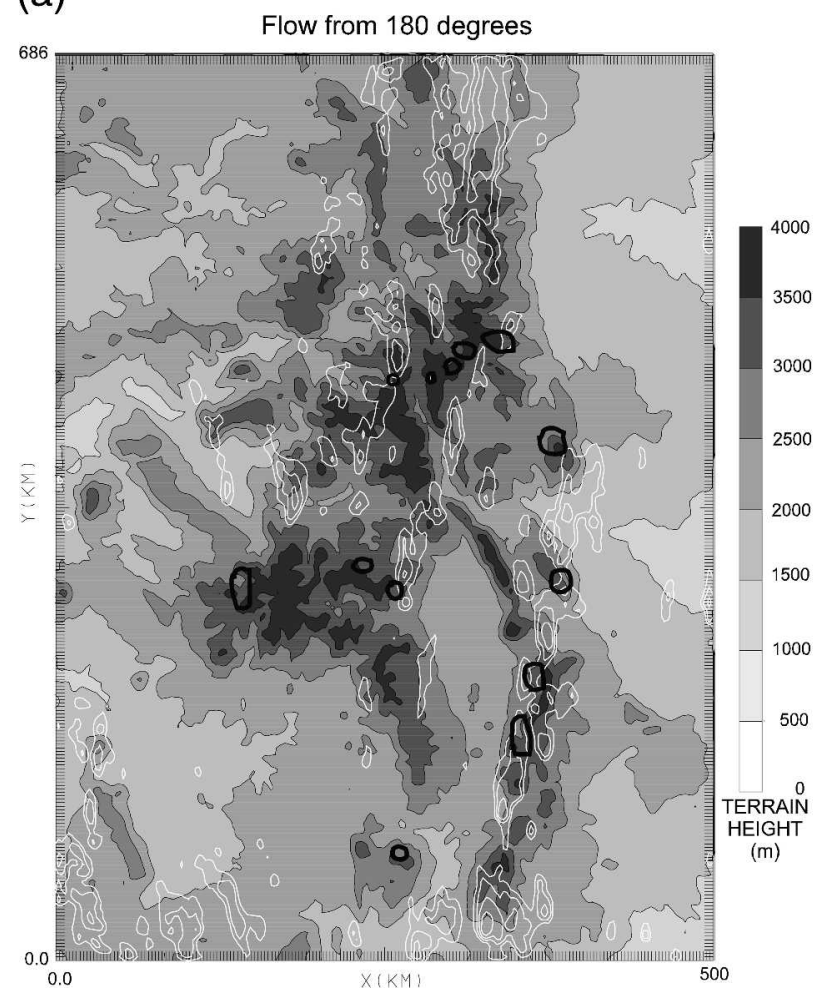

(c)

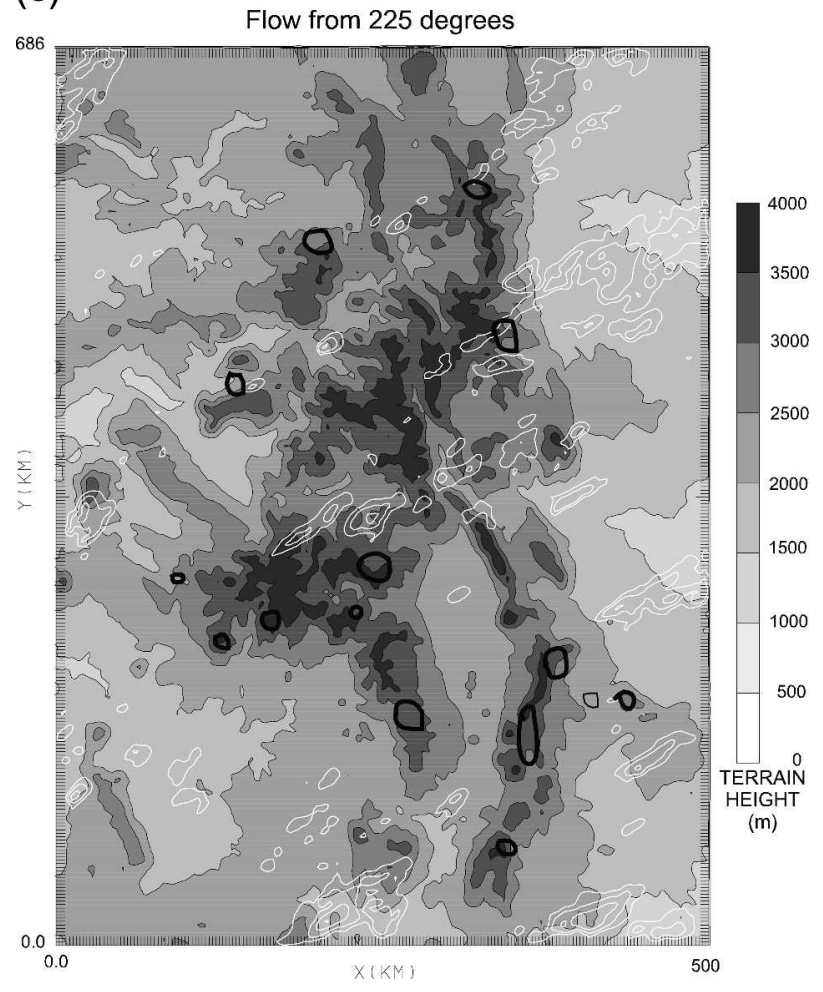

(b)

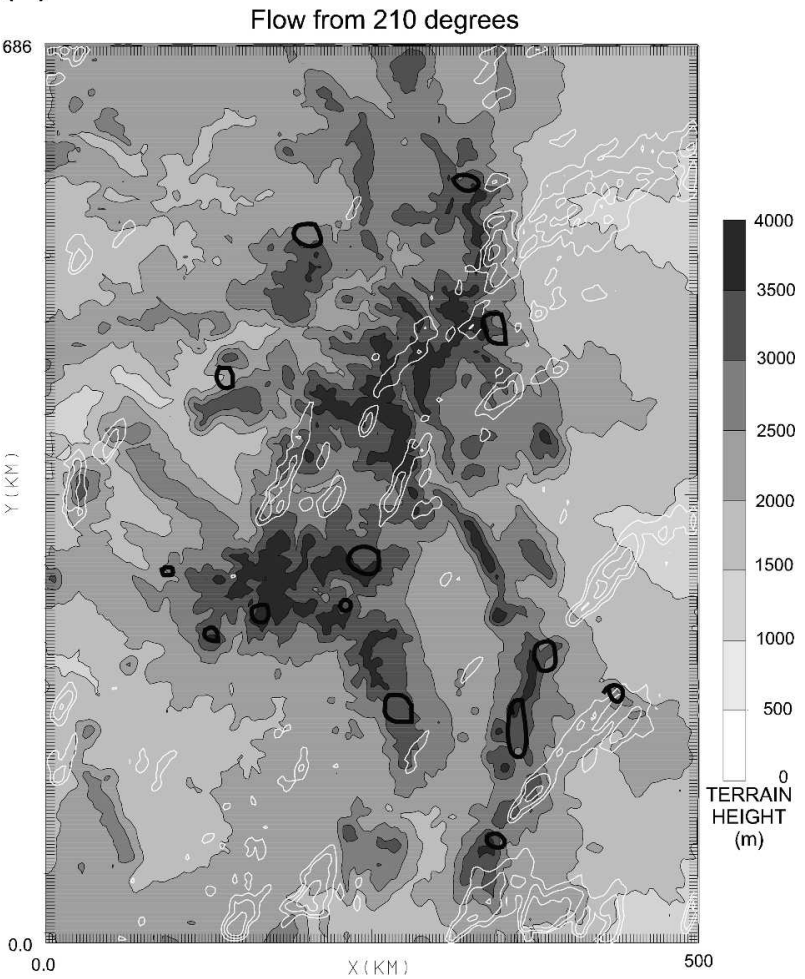

FIG. 7. Simulated precipitation accumulated over $12 \mathrm{~h}$. White contours are at 2, 4, 8, 16, and $32 \mathrm{~mm}$. Black contours are places of most frequent thunderstorm initiation as observed by Banta and Schaaf (1987). Initial winds are from (a) $180^{\circ}$, (b) $210^{\circ}$, (c) $225^{\circ}$, (d) $270^{\circ}$, and (e) $315^{\circ}$. 
(d)

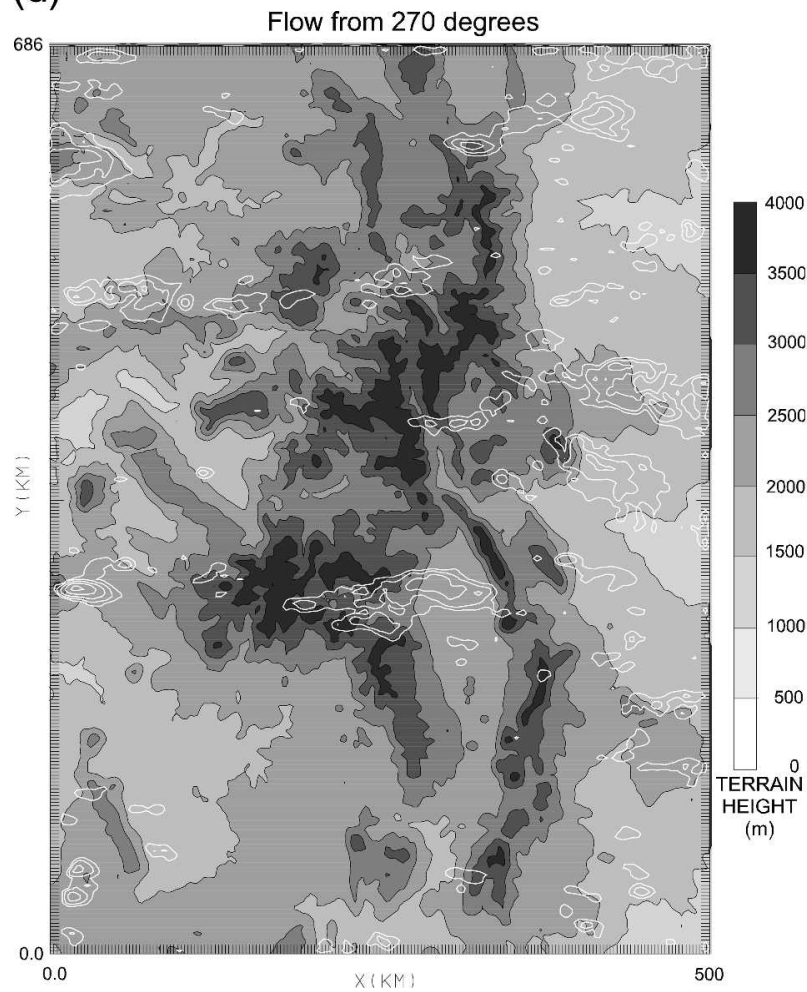

(e)

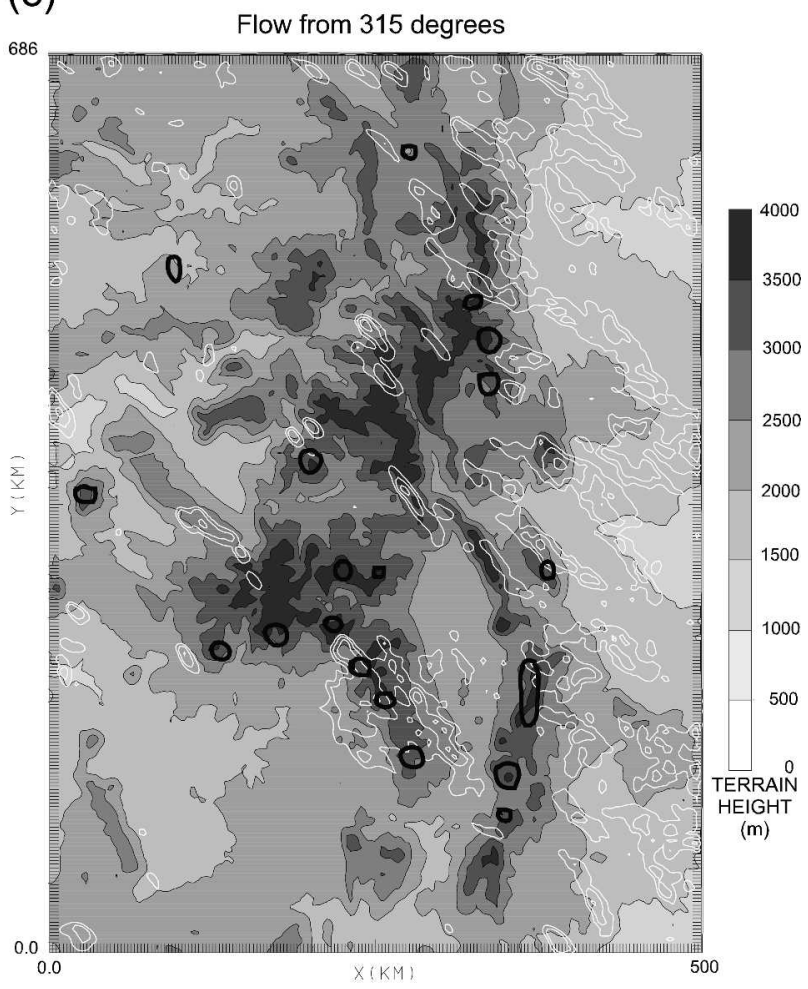

FIG. 7 (Continued)

from $315^{\circ}$. This precipitation pattern is unlike some others in the large number of places with relatively low precipitation. There are, however, a moderately high number of places where the precipitation is greater than $10 \mathrm{~mm}$. These simulations indicate that given the same moisture and stability conditions, this flow can produce more precipitation than any of others studied. In reality, flow from this direction usually occurs with more stable and drier conditions than those of the other flow directions. The large number of initiation sites mean that this flow pattern will initiate precipitating storms over a wide area and provide the most widespread precipitation if sufficient atmospheric moisture is present. This flow direction has

TABLE 1. The total precipitation, number of grid boxes with at least $0.5 \times 10^{-3} \mathrm{~m}$, and the precipitation per grid box in the inner domain for all cases (in $10^{-3} \mathrm{~m}$ ). Number of grid boxes with precipitation exceeding $10 \mathrm{~mm}$ - southern and western boundaries excluded.

\begin{tabular}{lccrr}
\hline \hline \multicolumn{1}{c}{ Case } & $\begin{array}{c}\text { Total } \\
\text { precipitation }\end{array}$ & $\begin{array}{c}\text { No. of boxes } \\
\text { with precipitation }\end{array}$ & $\begin{array}{c}\text { Precipitation } \\
\text { per grid box }\end{array}$ & $\begin{array}{r}\text { No. of boxes } \\
\text { with }>10 \text { mm }\end{array}$ \\
\hline $180^{\circ}$ & 34495 & 15135 & 2.21 & 106 \\
$210^{\circ}$ & 32356 & 14654 & 2.21 & 15 \\
$225^{\circ}$ & 28790 & 13716 & 2.10 & 6 \\
$240^{\circ}$ & 27442 & 12775 & 2.15 & 32 \\
$270^{\circ}$ & 33961 & 16019 & 2.12 & 42 \\
$300^{\circ}$ & 35063 & 17196 & 2.04 & 44 \\
$315^{\circ}$ & 42707 & 19679 & 2.37 & 58 \\
$330^{\circ}$ & 47333 & 20006 & 1.80 & 52 \\
$210^{\circ}$ with doubled wind speed & 17700 & 17026 & 2.49 & 0 \\
$210^{\circ}$ with halved wind speed & 42343 & 21347 & 2.03 & 156 \\
High CAPE with increased lapse rate & 43436 & 20853 & 2.77 & 52 \\
High CAPE with increased moisture & 57836 & & 234 \\
\hline
\end{tabular}


most of its convective initiation locations in the eastern part of the domain although precipitation in the northwestern part of the domain is greater than that of the more southerly flows. The flow from $300^{\circ}$ is qualitatively similar but has less overall precipitation. With its high number of initiation locations, it ends up with less precipitation per grid point than any of the other simulations with varying wind direction. Flow from the northwest occurs frequently in this region.

\section{e. Dependence on flow direction}

In Fig. 8a the domain-integrated accumulation is plotted against wind direction. As can be seen, given the same thermodynamic profile, the precipitation is minimized for southwesterly flow and maximized for northwesterly flow. The precipitation plots in Fig. 7 and the data in Table 1 also indicate that there are significantly more initiation locations for northwesterly flow than southwesterly flow. A possible reason for this difference is shown by Figs. 9a and $9 \mathrm{~b}$. These diagrams show the results of a wavelet analysis applied to the terrain heights [analysis performed by J. Tuttle and described in Gall et al. (1998)]. The analysis calculates the correlation of the terrain height with a wavelet function over a rectangular subdomain. The correlation function, $R(x, y, \theta)$, is given by (a)

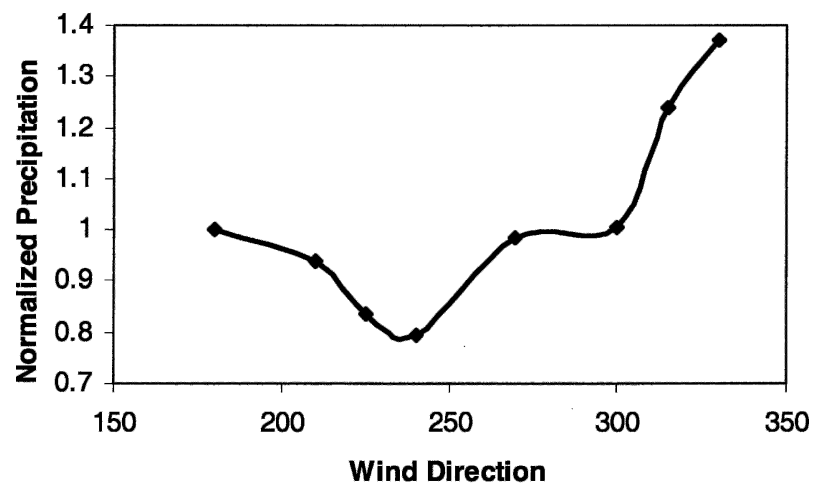

(b)

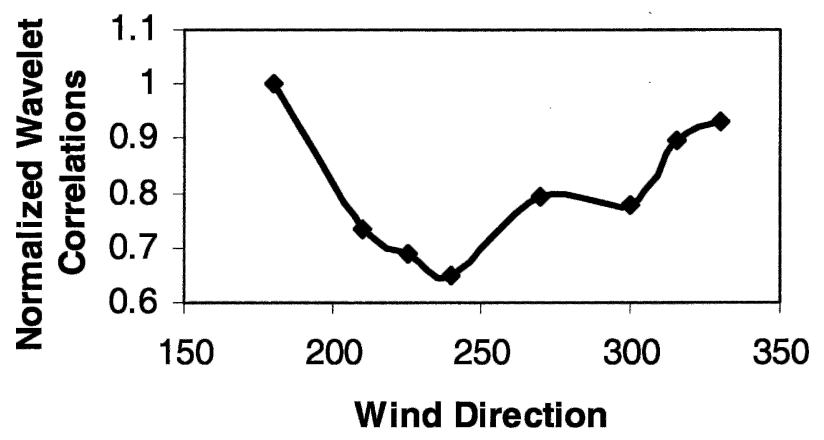

FIG. 8. (a) Integrated precipitation over the domain vs wind direction. (b) Wavelet correlations of terrain elevation vs wind direction.

$$
R(x, y, \theta)=\frac{\sum H(x+\Delta x, y+\Delta y) F(\Delta x, \Delta y, \theta)+n^{-1} \sum H(x+\Delta x, y+\Delta y) \sum F(\Delta x, \Delta y, \theta)}{\left\{\left[\sum H^{2}(x+\Delta x, y+\Delta y)-n \bar{H}\right]\left[\sum F^{2}(\Delta x, \Delta y, \theta)-n \bar{F}\right]\right\}^{0.5}}
$$

where $F=\cos \{(2 \pi / W)[\Delta x \cos (\theta)-\Delta y \sin (\theta)]\}$. Here $W$ is the width of the rectangular subdomain, and $\theta$ is the orientation of the rectangle relative to north. The summations are performed over all the grid points (of number, $n)$ in the rectangular subdomain. Finally, $(\Delta x, \Delta y)$ is the displacement from the center point of the rectangle $(x, y)$.

The wavelet, $F$, has the form of a ridge that has constant height along the major axis of the rectangular subdomain but takes the form of a cosine in the direction of the minor axis. The correlation analysis is performed for every point in the terrain file by moving the subdomain over the entire terrain file. Finally, separate correlation plots are calculated for different orientations, $\theta$, of the rectangular domain. The size of the domain is $60 \mathrm{~km}$ by $24 \mathrm{~km}$; a sample domain is plotted in the center of Fig. 5. This analysis will produce high correlation values where the mountain ridges are long and are oriented along the direction used for the analysis. Notice that the analysis does not consider the absolute height of the ridge, only its spatial variation. In Fig. 9a, the correlation function is shown for a southwest-northeast orientation and shows ridges that are oriented in that direction. Figure 9b shows the correlation function for a northwest-southeast orientation. As can be seen there are significantly more ridges in the Rocky Mountains that are aligned in a northwestsoutheast direction than in a southwest-northeast direction. It follows from the results presented in Part I that, given the same stability and wind speed conditions, more precipitation will be generated in the central Rocky Mountains when the flow is from the northwest.

The correlation analysis was performed for each wind direction used in the simulations. The correlations were then summed over the entire domain and then 
a) SW-NE Orientation

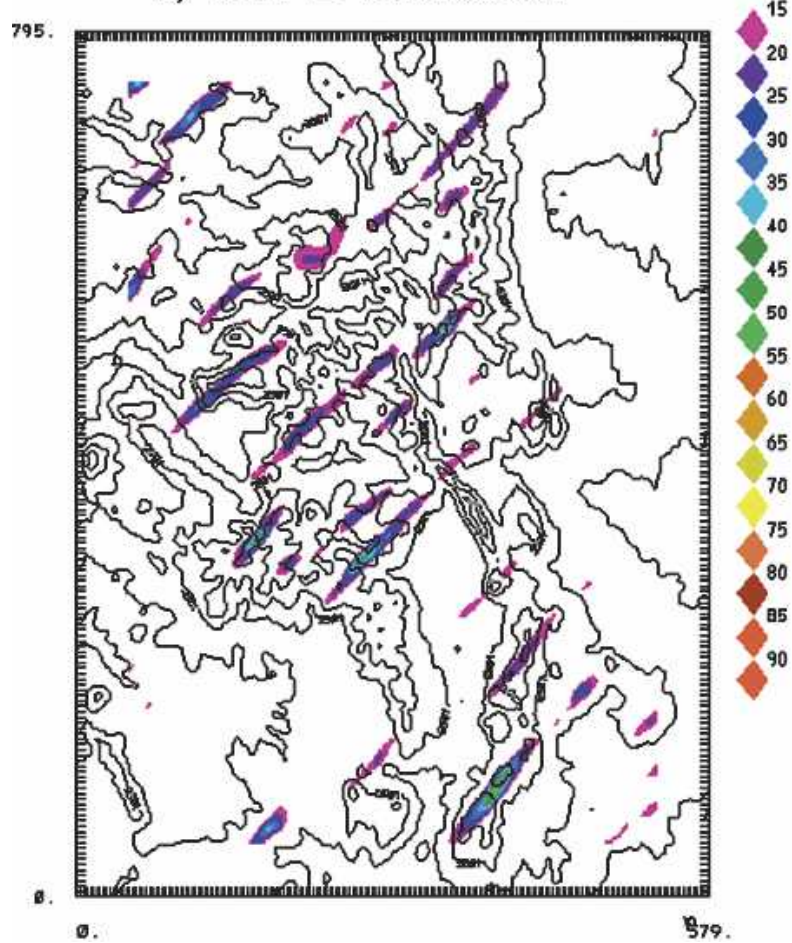

b) NW-SE Orientation

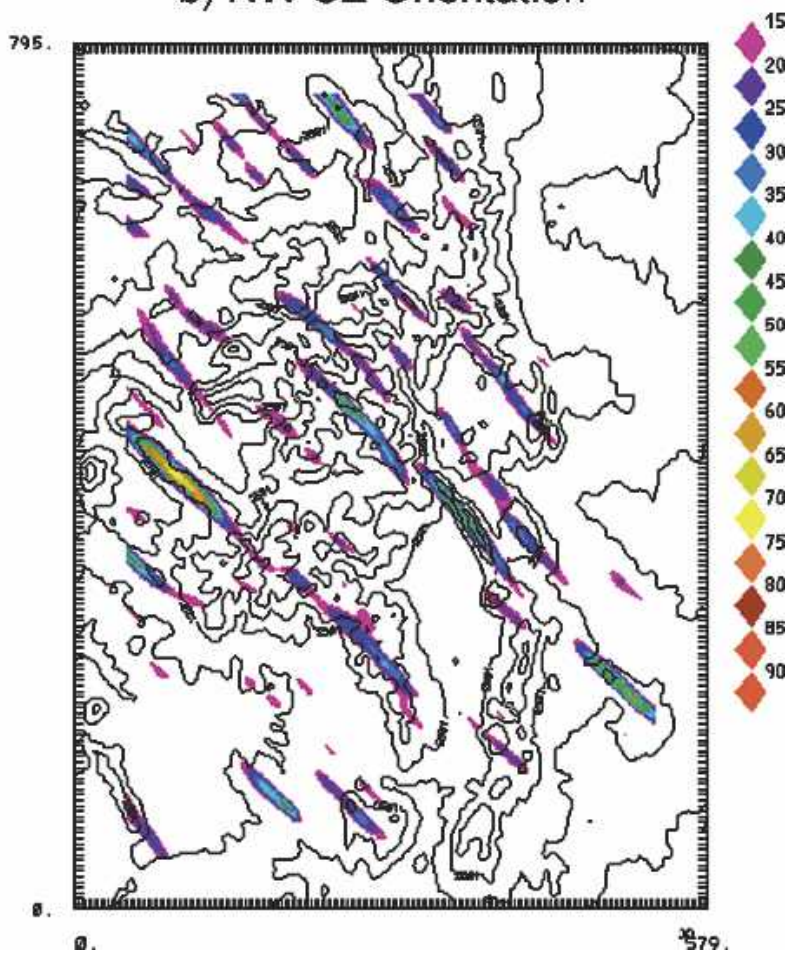

FIG. 9. Wavelet analysis of terrain heights in the study domain for (a) southwest-northeast orientation and (b) northwest-southeast orientation.

plotted against wind direction (Fig. 8b). Notice that there is close correspondence of the total precipitation amounts and the correlation sums. In a linear regression, the correlation coefficient of these two quantities is 0.74 , which is statistically significant $(\alpha=0.04)$. Thus, the length of the ridges in the direction of the wind strongly influences the amount of precipitation produced in the simulation over the domain. In addition, because of the high value of the correlation coefficient, the length of the ridges in the direction of the wind accounts for a substantial majority of the variation in the total precipitation produced between the cases.

\section{Sensitivity studies}

\section{a. Solar heating without orography dependence}

Because of the varying slope and aspect of mountainous terrain, the solar radiation received at the surface varies spatially. These differences may contribute to the formation of mountain-valley wind systems. The differences in the surface heating and the resulting winds could influence the formation and enhancement of precipitation systems. To compare the magnitude of this potential forcing mechanism on precipitation, we repeated the simulation with winds from $210^{\circ}$ but ex- cluded the effect of slope and aspect on the solar radiation absorbed by the earth's surface. The results after $12 \mathrm{~h}$ of simulation are presented in Fig. 10. It can be seen that Figs. 10 and $7 \mathrm{~b}$ are very similar, indicating that, for scales resolved by the model, the heating effects of variations in slope and aspect on the precipitation pattern are small compared to the effect of the length of the ridge that the air is traversing.

\section{b. Variation in wind speed}

As shown in Part I, the strength of convergence generated in the lee of heated orography is dependent on the wind speed. Figure 11 presents results from simulations at $210^{\circ}$ with wind speeds doubled and halved from those of the control simulation. The direction $210^{\circ}$ was chosen for these simulations because of its moderate precipitation amounts. Both increases and decreases in precipitation will be clearly different from the control.

With doubled wind speeds there are considerably fewer initiation locations than in the control simulation. The precipitation amounts are likewise much lower, showing that the thunderstorms that are generated are fairly weak. The total precipitation as well as the precipitation per grid box are reduced by about a factor of 


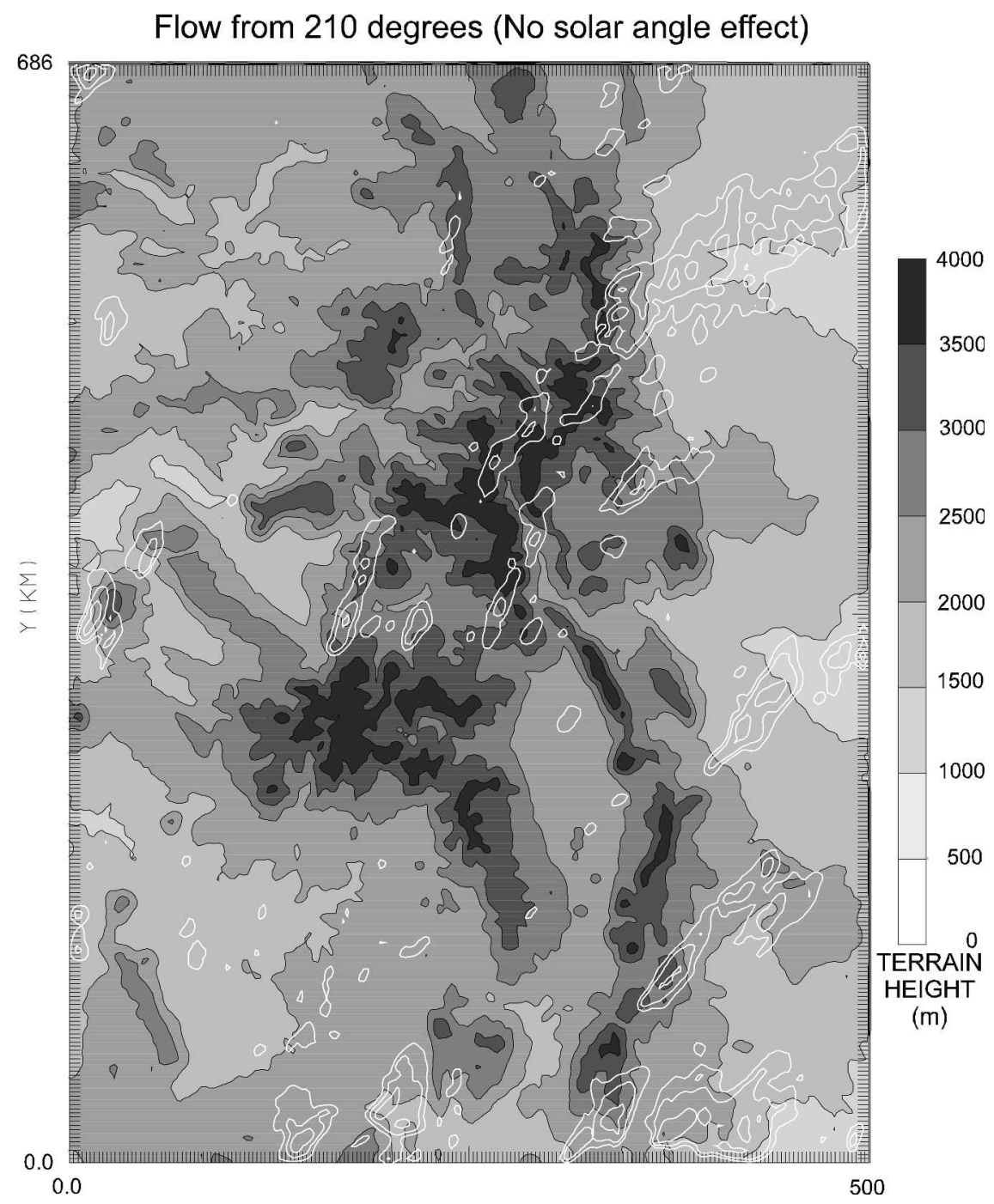

FIG. 10. As in Fig. $6 \mathrm{~b}$ but not including the effects of slope and aspect on the amount of solar radiation absorbed by the surface.

2. In Part I we showed that with stronger winds, the air is exposed to the elevated heating for a shorter period of time, which therefore reduces convergence in the lee.

The simulation with halved wind speeds reflects a large number of initiation locations. These include initiation locations on the east side of the San Juan Mountains and Pike's Peak. These initiation locations were not in the control $210^{\circ}$ simulation. This simulation with halved wind speeds indicate that these initiation locations are activated only at lower wind speeds. Although this wind speed yields extensive precipitation throughout the mountains, precipitation on the plains is less widespread than with winds from $270^{\circ}$ or $315^{\circ}$. The lower wind speeds do not allow many of the storms generated to propagate out to the plains before they die out. The halved wind speeds also dramatically increase the precipitation amounts as initiation locations increase and the slow movement of the storms leads to more precipitation per location. The number of grid boxes with precipitation over $10 \mathrm{~mm}$ increases dramatically, illustrating how much greater the potential for flash floods is with slower wind speeds.

The differences in the amount of precipitation per grid box between these simulations and the simulations where the wind direction varied reveal that the precipitation amounts at fixed locations are more sensitive to the wind speed than to the wind direction. Whether or not precipitation occurs at a particular location (independent of amount) appears to be about equally sensitive to wind speed and wind direction. 
(a)

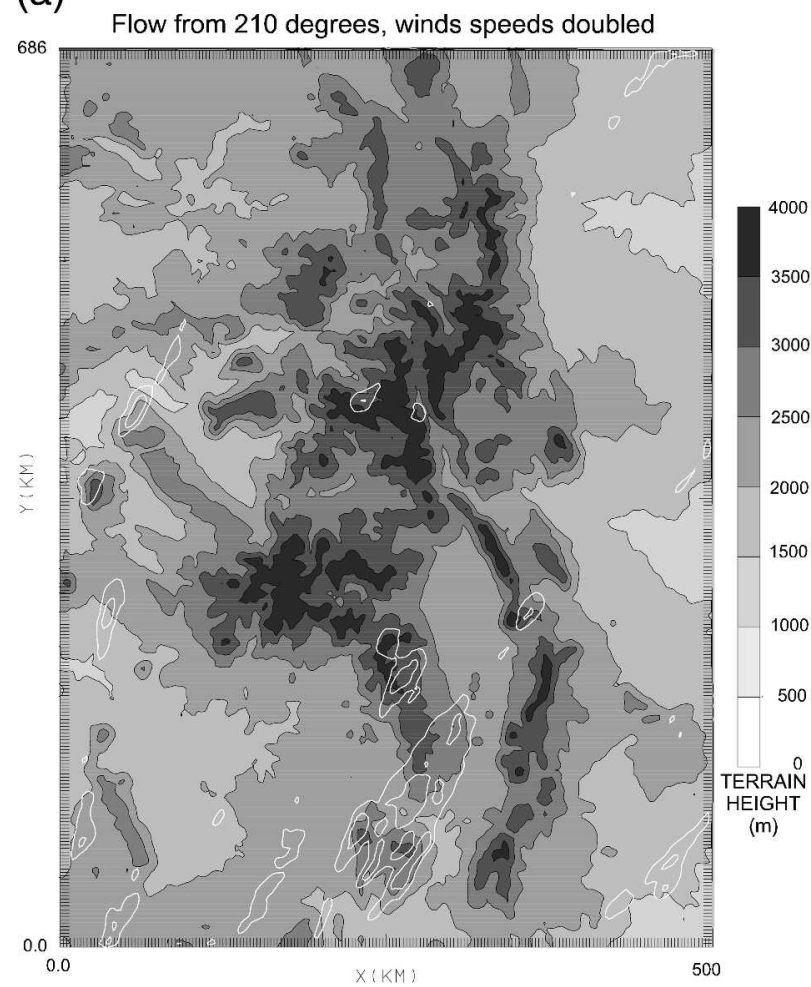

(b)

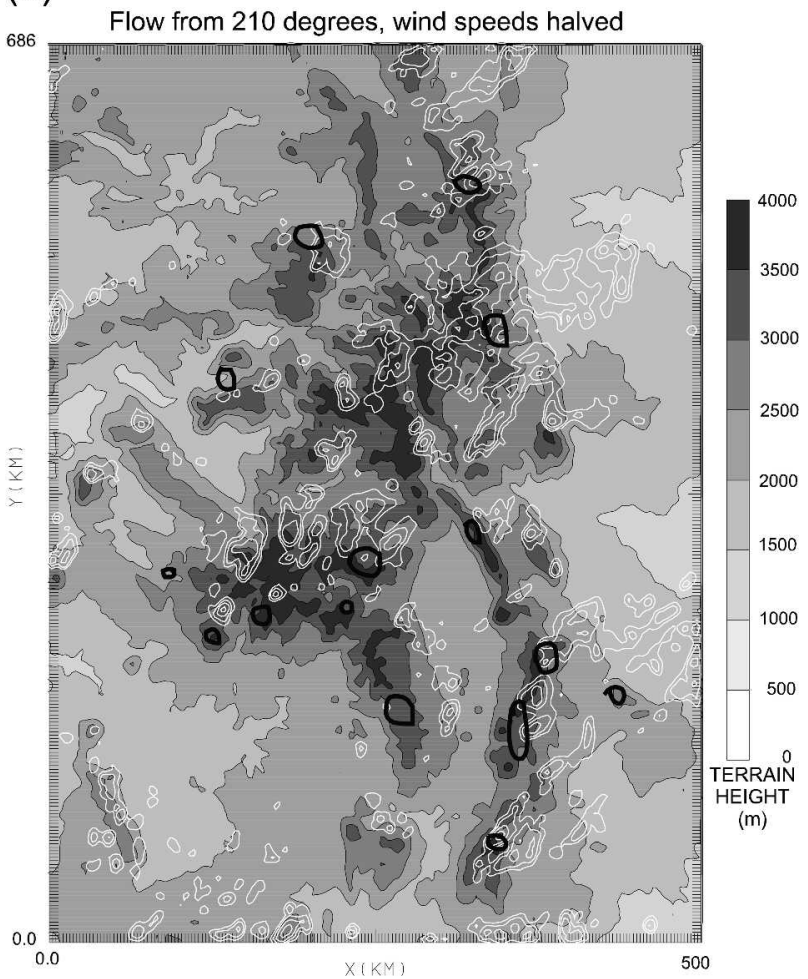

FIG. 11. Simulations from $210^{\circ}$ with wind speeds (a) double those of the simulation in Fig. $4 \mathrm{~b}$ and (b) half those of the simulation in Fig. 4b.

\section{c. Variations in atmospheric stability}

As was shown in section 3 , the precipitation pattern in the mountains depends strongly on the heatinginduced convergence generated on the lee side of the topographic features. If the moist stability is initially lower a weaker trigger may initiate convection. Therefore, convection should start earlier and more locations should be able to act as initiation locations. This section illustrates some of the effects of varying stability.

As in the preceding section we have performed our sensitivity studies with winds from $210^{\circ}$. Figure 12 shows a sounding with the same temperature profile as the control but with more moisture. This change increases the initial CAPE of the sounding to $1577 \mathrm{~J} \mathrm{~kg}^{-1}$. Figure 13 reveals that this simulation indeed has considerably more initiation sites than the control simulation. The pattern of initiation sites alone bears resemblance to the flow with halved wind speeds. But because this simulation had stronger winds, the precipitation extends downwind more from the initiation sites and the precipitation is spread over a wider area. Both the number of places with precipitation and the amount of precipitation per point are much larger than the control simulation and the simulation with halved wind speeds. However, since the storms move faster in this simulation, the number of grid points with greater than $10 \mathrm{~mm}$ of precipitation does not increase as dramatically as it did for the halved wind speed simulation.

In the preceding experiment it is difficult to determine if the increase in precipitation is due to an increase in the low-level moisture or to an increase in CAPE. To differentiate between the two, we have performed an experiment with increased CAPE while keeping the low-level moisture the same as in the control experiment. Figure 14 presents a sounding whose stability was decreased by increasing the temperature lapse rate; the dewpoint profile remained the same. Therefore, no additional moisture was available for precipitation. This sounding has CAPE of $705 \mathrm{~J} \mathrm{~kg}^{-1}$ it is more difficult to increase the conditional instability by increasing the lapse rate than by adding moisture. The total amount of precipitation in this simulation (Fig. 15) is slightly larger than that of the simulation with halved wind speeds but the amount of precipitation per grid box is smaller. This simulation had the largest number of points with precipitation-yet the downwind spread of the precipitation is not as great as 


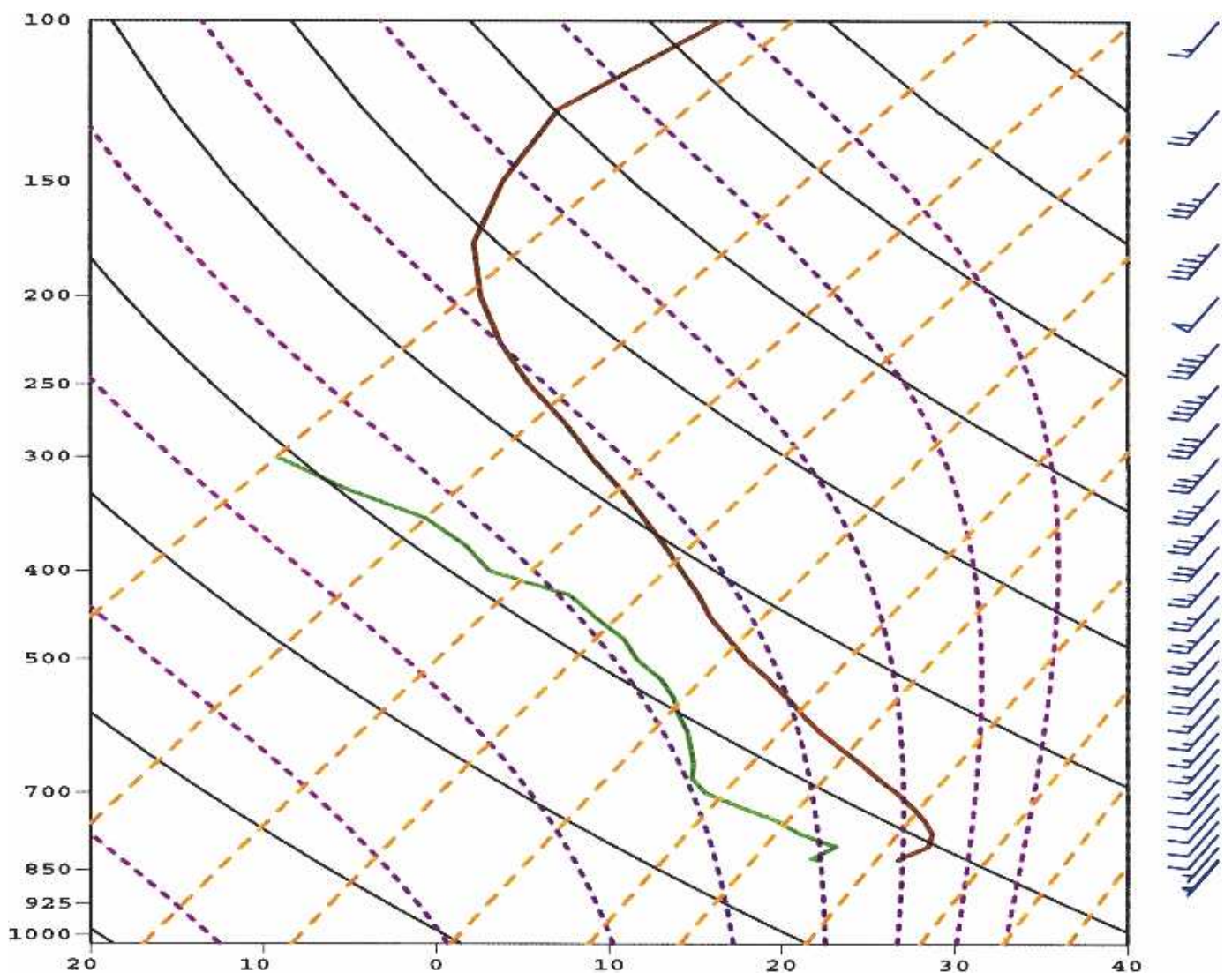

FIG. 12. Skew $T-\log p$ diagram of sounding with increased moisture near the surface. CAPE $=1577 \mathrm{~J} \mathrm{~kg}^{-1}$.

in the simulation shown in Fig. 13. Many of the storms do not last long enough to spread precipitation downwind. Evidently either the greater moisture or the greater CAPE enabled stronger thunderstorm outflow to form, which was more likely to initiate thunderstorms downstream. With a large lapse rate, as in the simulation shown in Fig. 15, weaker convergence is able to initiate convection. Thus a ridge with a shorter wind component in the direction of the wind is able to initiate precipitation under these circumstances. These simulations with larger CAPE illustrate some of the differences that could be expected as lapse rate and atmospheric moisture vary from place to place.

\section{Comparison with observations}

We would also like to compare our results to the initiation locations found by Banta and Schaaf (1987). The most frequent initiation sites they observed are shown by thick black contours overlaid on Figs. 7a-c, $7 \mathrm{e}$, and 11b. The initiation locations associated with their curving southerly regime are plotted on the $180^{\circ}$ plot, those associated with their southwesterly regime are plotted on the $210^{\circ}$ and $225^{\circ}$ plots, and those associated with the northwesterly regime are plotted on the $315^{\circ}$ plot. An exact comparison is not possible because Banta and Schaaf's results are grouped into only three wind regimes and each regime represents a continuum of wind directions. Banta and Schaaf's results also did not consider the effects of wind speed. In addition, their results represent the number of times initiation occurred over a long period of days. Our results represent where convection would occur on one typical day. Thus, our results represent situations that may occur infrequently in Banta and Schaaf's data. Likewise some of their results may represent situations we have not explicitly shown. Nevertheless, a qualitative comparison is possible. We identify the precipitation initiation locations by the upwind end of the precipitation streaks in Figs. 7 and 11.

Banta and Schaaf's curving southerly flow should correspond to our simulation with winds from $180^{\circ}$, and to a certain extent the $210^{\circ}$ simulation. As can be seen from Fig. 7a, many of the initiation sites found by Banta and Schaaf for curving southerly flow also show up in our $180^{\circ}$ simulation. In particular, the observed initiation along the Sangre de Christo, eastern San Juan, and 


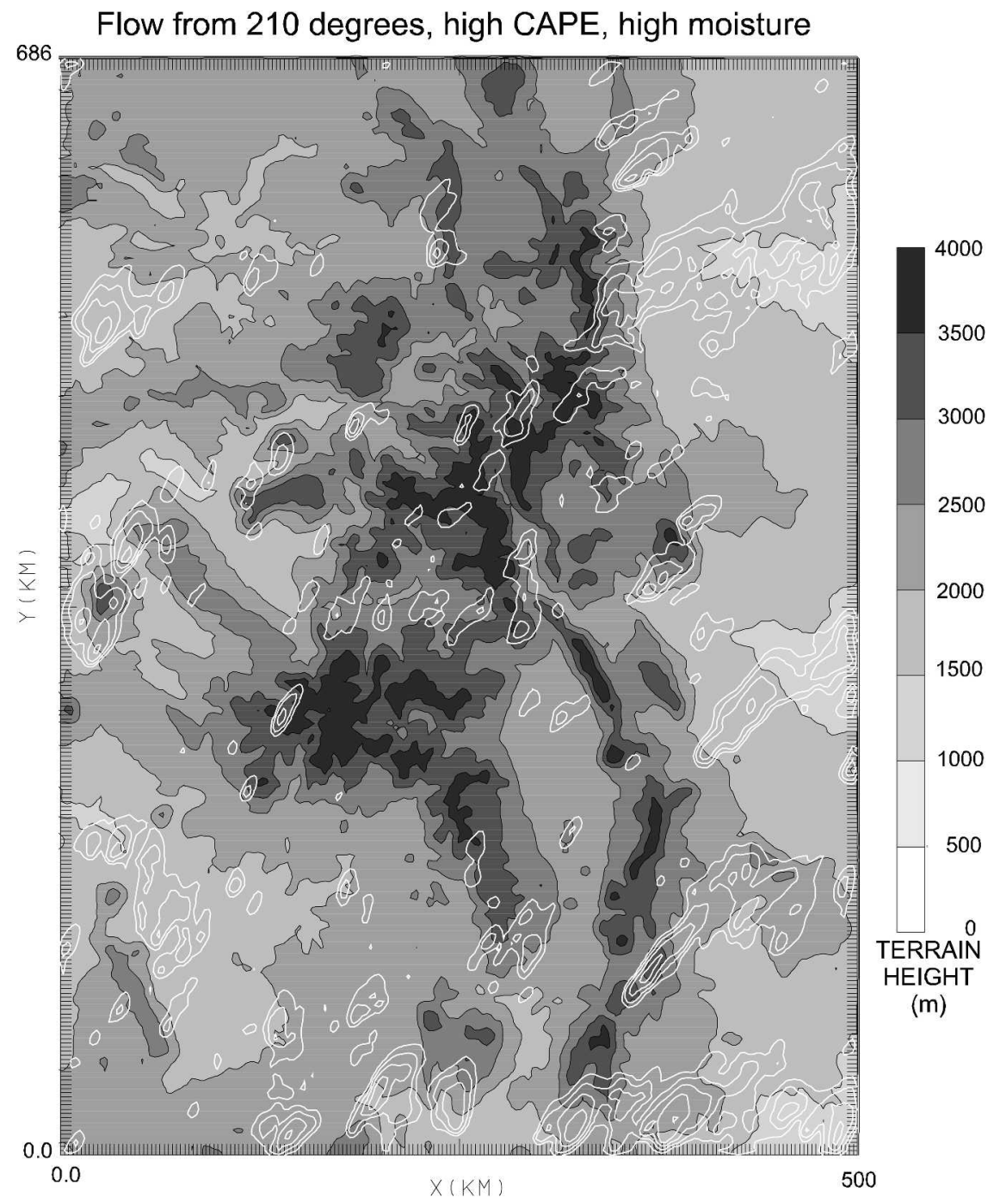

FIG. 13. Simulation of 12-h precipitation from sounding in Fig. 12.

northern Sawatch sites are replicated in the $180^{\circ}$ simulation. Banta and Schaaf's results also show that the Ten Mile ridge is a strong initiator in curving southerly flow. Although this initiation does not show up in our $180^{\circ}$ simulation, it is prominent in the $210^{\circ}$ run. Pike's Peak and the eastern and western San Juan Mountains do not initiate convection in the control simulations but do with reduced wind speeds at $210^{\circ}$; see Fig. $11 \mathrm{~b}$.

Banta and Schaaf's southwesterly flow should correspond to our $210^{\circ}, 225^{\circ}$, and $240^{\circ}$ simulations. The initiation they show over Grand Mesa appears in our $240^{\circ}$ simulation (not shown). Initiation over the Sangre de Christo Mountains and northeast of the Roan Plateau also appears on the $240^{\circ}$ simulation. Banta and Schaaf's southwesterly flow has initiation over the Ten Mile ridge but not as strong as for curving southerly flow. This feature is consistent with our $225^{\circ}$ simulation. Our simulations have initiation from the San Juan Mountains farther to the north than in Banta and Schaaf's observations but still farther south than for the $180^{\circ}$ simulation.

Our simulation from $315^{\circ}$ has numerous initiation points. It has more initiation points in the northeast part of the domain than Banta and Schaaf's observations for northwest winds. As was mentioned above, it was carried out with more moisture than is typical for flow from $315^{\circ}$ so that it would be directly comparable with flows from the other directions. Nevertheless, both our and Banta and Schaaf's results show more initiation points in the northwest part of the domain than for other flow directions. Likewise, both show that convective initiation is more common on the southeastern side of the San Juan Mountains and the eastern side of the Sangre de Christo. 


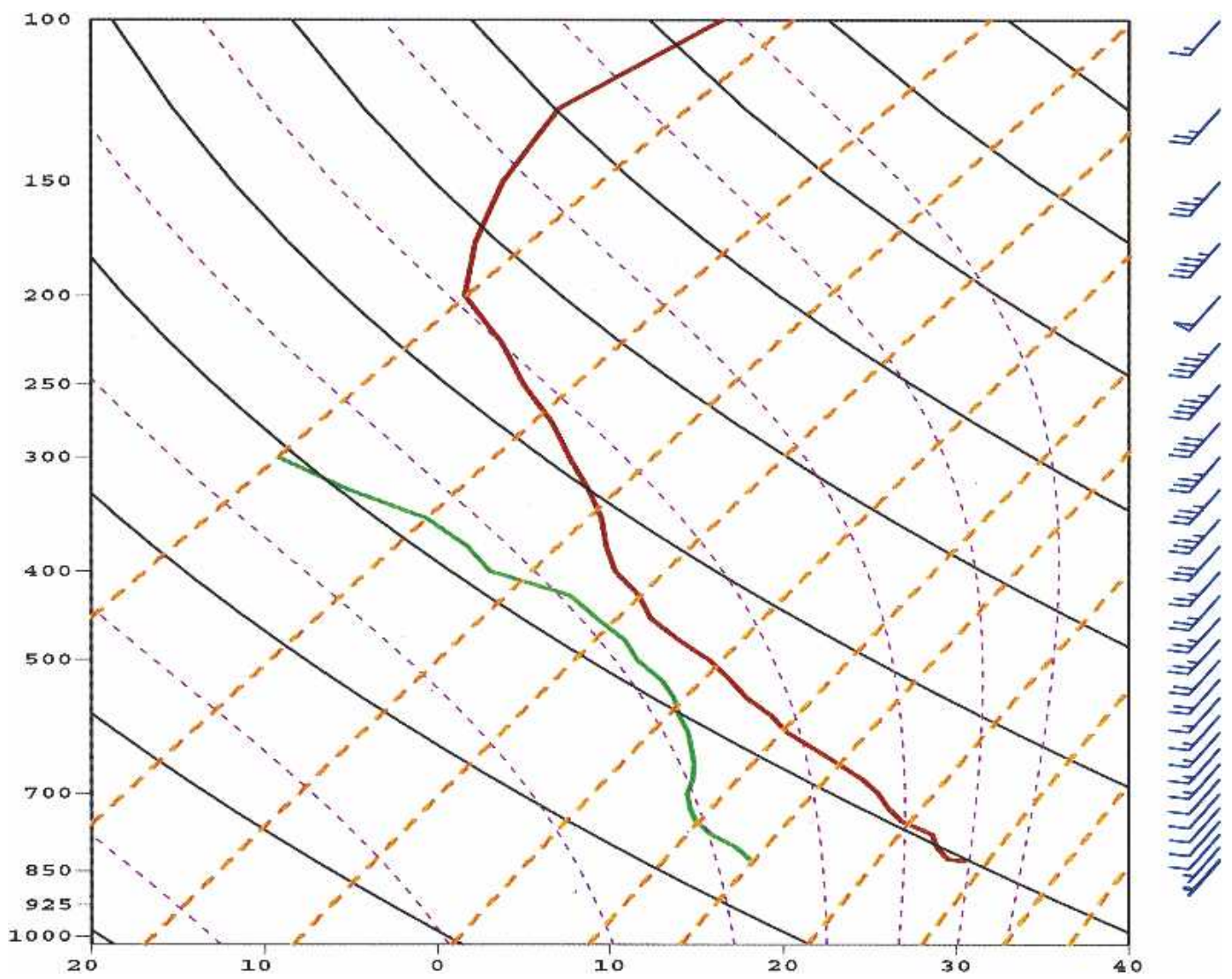

FIG. 14. Skew $T-\log p$ diagram of sounding with increased lapse rate near the surface. CAPE $=705 \mathrm{~J} \mathrm{~kg}^{-1}$.

Although a quantitative evaluation with Banta and Schaaf's observations is not possible, these comparisons do suggest that a large part of the day-to-day variablility in the locations of convective initiation can be accounted for by differences in the wind direction and speed.

\section{Conclusions}

This study has shown that variations in wind direction, wind speed, and atmospheric stability result in substantial variations in the locations where precipitating summer thunderstorms initiate in the Rocky Mountains and in the amount of precipitation they produce. These variations are primarily caused by differences in the length of time the air is exposed to the heatinginduced convergence on the lee side of the mountain ridge. Air that spends more time over elevated heating is exposed to more convergence and is more likely to develop into a convective storm. Mountain ridges that have their highest terrain oriented parallel to the wind direction are most likely to generate convection. Comparison of our results with the observations of Banta and Schaaf (1987) illustrates that variations in wind di- rection, wind speed, and atmospheric stability can explain a large part of the variation in thunderstorm initiation locations in the complex terrain. This finding demonstrates that the effects of the mountains on airflow noted in Part I are important in determining convective initiation locations in the real atmosphere.

The effects of variations in wind direction were examined in detail because the wind direction determines the physical length of the flow along a ridge. Some topographic features were able to initiate convection from a variety of directions but others would require that the wind be from a particular direction. The wind direction controlled the locations and to a lesser degree the amount of precipitation. The wind directions were all examined with the same sounding even though in reality some wind directions tended to be associated with higher instability than others. This simplification allowed us to isolate the dependence on flow direction. This method illustrated that northwest flow has a greater potential to produce precipitation than other wind directions we examined, although the precipitation per grid box was moderate. Winds from $225^{\circ}$ and $240^{\circ}$ occur with moderate frequency over the Rocky Mountains in the summer but have the least potential 


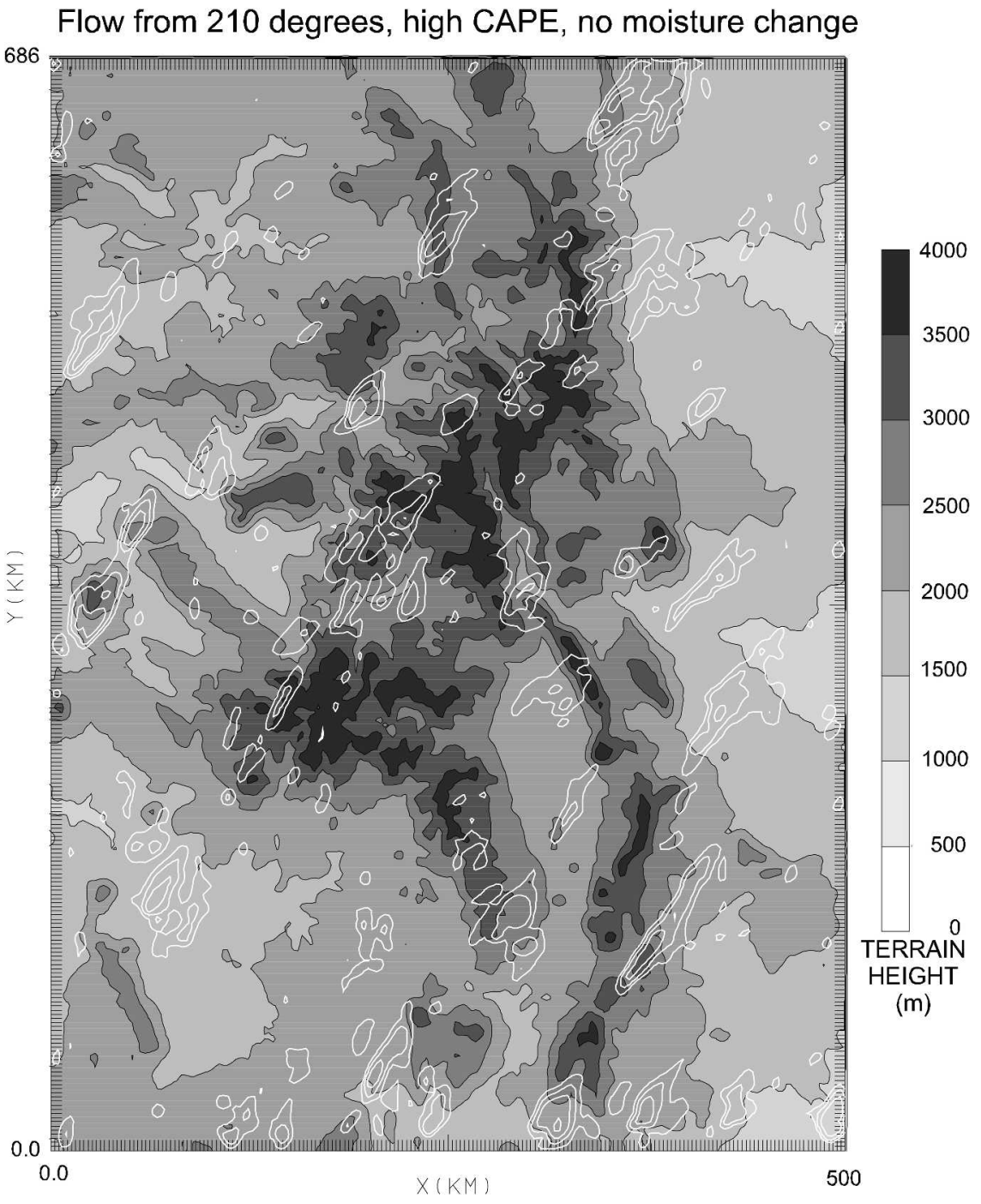

FIG. 15. Simulation of 12-h precipitation from sounding in Fig. 14.

to produce precipitation. A possible explanation for the greater efficiency of northwest flow over southwest flow is the greater number of ridges in the Rocky Mountains that are aligned in a northwest-southeast direction.

Wind speed is also important in determining convective initiation locations in complex terrain. Slower wind speeds lead to the air spending more time in elevated heating and encourage the development of precipitating thunderstorms. With slower wind speeds the convection propagates downwind at a slower speed and tends to produce more precipitation in each location. Faster winds are associated with fewer convective initiation locations but storms generated may bring precipitation to a larger area because the storms propagate downwind more rapidly.

Increasing atmospheric instability increases the amount of precipitation over the domain but how the precipitation increases is related to how the instability is increased. Greater temperature decrease with height leads to more convective initiation locations but a decrease in the precipitation per storm. Increasing the dewpoint can lead to much larger increases in precipitation, especially in the amount of precipitation per storm. Convection spreads downwind more readily if more atmospheric water vapor is present and/or the CAPE is higher. The simulations with different values of CAPE can give some indication of the variations expected if horizontal temperature and moisture differences are present.

It is important to note that the simulations presented in this paper were done without any synoptic forcing. Frontal systems, vorticity maxima, inertial gravity waves, and other disturbances that vary from day to day 
could alter the patterns illustrated in these simulations significantly. There are many days during the summer in this region, however, when synoptic forcing is weak and yet a fair amount of precipitation falls. In addition, thunderstorm initiation can be influenced by topographic features or processes not resolved by the size of the model grid used in this study. Spatial variations in atmospheric moisture were not included in this study and they can be important influences on convective initiation in this region. This study was performed with a constant Bowen ratio. In reality the Bowen ratio varies widely in space and time. Forcing mechanisms associated with convective initiation become more complicated on the adjacent high plains where thunderstorm outflow is a significant initiation mechanism. Whether thunderstorm outflow will initiate a new convection depends on a number of factors, many of whose daily variations are not well known (Tucker and Crook 1999).

These results yield some insights as to why some locations in the central Rocky Mountains will receive abundant rainfall while a location nearby may receive less than normal precipitation. The frequency with which the different wind directions and wind speeds occur varies from year to year. If a certain wind direction predominates one season, then locations that are favored for precipitation under that wind regime may receive above-average rainfall that season.

These results can be helpful for day-to-day weather forecasting when synoptic forcing is weak. By examining the midtropospheric wind direction the forecaster can anticipate which regions will be most favorable for precipitation on a particular day. Although we have concentrated on the Rocky Mountains, the results of Part I cause us to be optimistic that these convective initiation principles will be useful over other mountain ranges that have strong solar heating, provided the atmospheric conditions are fairly uniform.

Acknowledgments. This work was supported by NSF Grant ATM-9818161. We gratefully acknowledge John Tuttle who provided the wavelet correlation analysis software.

\section{REFERENCES}

Banta, R. M., 1990: The role of mountains in making clouds. Atmospheric Processes over Complex Terrain, Meteor. Monogr., No. 45, Amer. Meteor. Soc., 229-323.

— , and C. L. B. Schaaf, 1987: Thunderstorm genesis zones in the Colorado Rocky Mountains as determined by traceback of geosynchronous satellite images. Mon. Wea. Rev., 115, $463-476$.

Clark, T. L., and W. D. Hall, 1991: Multi-domain simulations of the time dependent Navier-Stokes equation: Benchmark er- ror analyses of nesting procedures. J. Comput. Phys., 92, 456481.

— and - 1996: On the design of smooth, conservative vertical grids for interactive grid nesting with stretching. J. Appl. Meteor., 35, 1040-1046.

Crook, N. A., and D. F. Tucker, 2005: Flow over heated terrain. Part I: Theory and idealized simulations. Mon. Wea. Rev., 133, 2552-2564.

Gall, R., J. Tuttle, and P. Hildebrand, 1998: Small-scale spiral rainbands observed in Hurricanes Andrew, Hugo and Erin. Mon. Wea. Rev., 126, 1749-1766.

Henz, J. F., 1973: Characteristics of severe convective storms in Colorado's High Plains. Preprints, Eighth Conf. on Severe Local Storms, Denver, CO, Amer. Meteor. Soc., 96-103.

Johnson, R. H., and B. E. Mapes, 2001: Mesoscale processes and severe convective weather. Severe Convective Storms, Meteor. Monogr., No. 50, Amer. Meteor. Soc., 71-122.

Karr, T. W., and R. L. Wooten, 1976: Summer radar echo distribution around Limon, CO. Mon. Wea. Rev., 104, 728-734.

Klitch, M. A., J. F. Weaver, F. P. Kelly, and T. H. VonderHaar, 1985: Convective cloud climatologies constructed from satellite imagery. Mon. Wea. Rev., 113, 326-337.

Koenig, L. R., and F. W. Murray, 1976: Ice-bearing cumulus cloud evolution: Numerical simulation and general comparison against observations. J. Appl. Meteor., 15, 747-762.

Lilly, D. K., 1962: On the numerical simulation of buoyant convection. Tellus, 14, 148-172.

Lopez, R. E., and R. L. Holle, 1986: Diurnal and spatial variability of lightning activity in northeastern Colorado and central Florida during the summer. Mon. Wea. Rev., 114, 1288-1312.

Maddox, R. A., F. Canova, and L. R. Hoxit, 1980: Meteorological characteristics of flash flood events over the western United States. Mon. Wea. Rev., 108, 1866-1877.

Reap, R. M., 1986: Evaluation of cloud-to-ground lightning data from the western United States for the 1983-1984 summer seasons. J. Climate Appl. Meteor., 25, 785-799.

Reiter, E. R., and M. Tang, 1984: Plateau effects on diurnal circulation patterns. Mon. Wea. Rev., 112, 638-651.

Smagorinsky, J., 1963: General circulation experiments with the primitive equations. I: The basic experiment. Mon. Wea. Rev., 91, 99-164.

Stephens, G., 1984: The parameterization of radiation for numerical weather prediction and climate models. Mon. Wea. Rev., 112, 826-867.

Szoke, E. J., M. L. Weisman, J. M. Brown, F. Caracena, and T. W. Schlatter, 1984: A subsynoptic analysis of the Denver tornadoes of 3 June 1981. Mon. Wea. Rev., 112, 790-808.

Tang, M., and E. R. Reiter, 1984: Plateau monsoons of the Northern Hemisphere: A comparison between North America and Tibet. Mon. Wea. Rev., 112, 617-637.

Tripoli, G. J., and W. R. Cotton, 1989a: Numerical study of an observed orogenic mesoscale convective system. Part I: Simulated genesis and comparison with observations. Mon. Wea. Rev., 117, 273-304.

— , and — 1989b: Numerical study of an observed orogenic mesoscale convective system. Part II: Analysis of governing dynamics. Mon. Wea. Rev., 117, 304-328.

Tucker, D. F., 1993: Diurnal precipitation variations in south central New Mexico. Mon. Wea. Rev., 121, 1979-1991.

_ vective system from mountain convection. Mon. Wea. Rev., 127, 1259-1273. 